\title{
Burden of illness of rheumatoid arthritis in Latin America: a regional perspective
}

\author{
L. A. Ramírez ${ }^{1}$ C. Rodríguez ${ }^{2}$ - M. H. Cardiel $^{3}$
}

Received: 17 February 2015 /Revised: 10 April 2015 / Accepted: 17 May 2015 / Published online: 30 July 2015

(C) The Author(s) 2015. This article is published with open access at Springerlink.com

\begin{abstract}
Rheumatoid arthritis (RA) is one of the most important rheumatic diseases. Its prevalence varies among ethnic groups. Genetic and environmental factors influence its incidence and prevalence. This chronic disease will increase its frequency in the future due to population aging. The personal impact of this disease on many relevant areas of an individual requires special efforts to prevent and treat it properly. Adequate advice on several recently described risk factors such as tobacco and alcohol exposure, infections, obesity, and physical exercise should be part of every medical consultation. This knowledge should be incorporated to improve health care prevention programs. Patients and clinicians must work together through better communication skills to finally improve outcomes. Including RA in priority health care lists will need special effort from rheumatology societies and better communication with policy makers.
\end{abstract}

Keywords Costs $\cdot$ Epidemiology $\cdot$ Patient experience · Priority health problems $\cdot$ Rheumatoid arthritis

Rheumatoid arthritis (RA) is a chronic autoimmune disease of unknown origin. Multiple factors have been proposed to interact to produce a systemic disease that is characterized by joint pain and swelling and a myriad of multiple manifestations

M. H. Cardiel

mhcardiel@hotmail.com

1 Sección de Reumatología, Universidad de Antioquia, Medellín, Colombia

2 Fundación Memuevo, Santiago, Chile

3 Centro de Investigación Clínica de Morelia, Virrey de Mendoza 1998-Int 522. Col, Félix Ireta, CP 58070 Morelia, Michoacán, Mexico outside the joints. If not properly treated, this joint swelling will produce damage and progressive disability. Life expectancy is also diminished [1].

RA prevalence is around $1 \%$ in the world but this number changes in different ethnic populations. In Mexico, one study using COPCORD methodology in 19,213 individuals, in five different regions, found a global prevalence of $1.6 \%$ with a different prevalence rate ranging from $0.7 \%$ (95\% confidence interval (CI): 0.5-1.0) in Nuevo León to $2.8 \%$ (95 \% CI: $2.3-$ 3.3) in Yucatán [2]. In Luján, Argentina, a city of 70,000 inhabitants, a prevalence rate of $0.94 \%$ (95\% CI: $0.86-$ $1.02 \%$ ) was found.

[3]. An interesting study recently done in 1656 Toba individuals living in Rosario, Argentina, found a prevalence of 2.4 (95\% CI: 1.7-3.2) [4]. These findings of increased prevalence in Yucatán, México, rich in original Mayan population and in Toba population in Argentina have raised increased interest in genetic, anthropologic, and environmental factors in the development of RA in original populations in our region. Multiple studies are currently undergoing in several Latin American countries including Argentina, Mexico, and Venezuela in an initiative called GLADERPO (Grupo LAtinoamericano De Enfermedades Reumáticas en Poblaciones Originales).

Incidence rates of RA are scarce in Latin America A recently published study in Ontario in 97,499 Ontarians found a cumulative prevalence of $0.9 \%$. Age- and sex-standardized RA prevalence increased steadily over time from 473 (95\% CI: 469-478) per 100,000 population (0.49\%) in 1996 to 784 (95\% CI: 779-789) per 100,000 population (0.9\%) in 2010. Age- and sex-standardized incidence per 100,000 population ranged from 62 (95\% CI: 60-63) in 1996 to 54 (95\% CI: 5255) in 2010 [5]. 
RA is the prototype of chronic diseases It is very important to be aware of multiple risk factors that have been described and intervene in those that are modifiable in order to improve patient outcomes. A brief description of the most commonly cited and recently described is presented.

Genetics It is well recognized that rheumatoid arthritis has a clear association with some genetic markers [6]. The shared epitope is one of the most studied but there are other genes that have been identified such as the PTPN22 [7]. Some protective genes have been described in Chinese population from Taiwan [8]. Some new genes have been detected in Latin American populations [9]. Although there have been important research studies in this area, no direct clear benefit has been offered to our patients with this knowledge yet. It is estimated that genes do not explain the great majority of RA cases.

Environmental factors Intensive and active research has been given to multiple environmental factors that have been identified as associated with the development of rheumatoid arthritis. The most studied have been hormonal, tobacco, alcohol, infections, toxic and pollutant agents, obesity, and physical exercise. Updated information is presented.

Tobacco It has been established that tobacco is a risk factor for RA development and particularly linked with a seropositive disease [10]. It has been described that this association is clearly related with genetic markers. Clinicians should be aware of smoking habits in their patients, and cessation programs should be implemented. It has been suggested that RA patients who continue smoking have less therapeutic clinical response [11].

Alcohol Mild to moderate alcohol consumption has been associated with a protective effect on RA development when compared to no or high alcohol consumption [12]. Some possible explanations have been offered, and immune modulation and anti-inflammatory actions are the most plausible theories. Although it is quite difficult to advise alcohol consumption, clinicians could identify the potential benefit of a low to moderate intake that seems to be particularly beneficial in women in a recent meta-analysis [13].

Infections An increased interest in infections has gained relevance in the last decade as a risk factor for RA development. There is supporting evidence that Porphyromonas gingivalis is associated with seropositive disease due to the citrullination capabilities of this bacterium [14]. Some studies have also shown that this association is related with disease activity [15]. Increased interest in gut microbiome has gained intense research attention in the last years in some diseases such as RA, psoriasis, obesity, and metabolic syndrome. These findings are quite promising since they offer clear practical possibilities for therapeutic interventions.

Toxic and pollutants Some studies have identified increased RA in some areas or human activities, where exposure to pollutants has been described. This has been detected in urban areas [16], exposure to insecticides [17], and also related to a low socioeconomic status [18]. The explanation of this interaction has been proposed to be through epigenetic changes in immune response genes. This piece of knowledge will be very important to design possible reversibility of these genetic modifications in the future. A clinician should be aware of this and give proper advice to patients and their families.

Obesity This recently described risk factor [19] is very important in Latin America when we are facing increasing obesity problems even starting in childhood. It has been postulated that obese subjects have an increased risk for RA development, and obese subjects have a decreased chance to reach remission or a low disease activity state [20]. Some data are also available describing that obese subjects have a lower rate of joint damage progression that has raised some possible metabolic explanations [21]. This area of intervention is one of the most important to be emphasized in a clinical setting.

Physical activity A recently published study described that patients who have been physically active during the past 5 years previous to RA development had a milder disease compared to those subjects who were sedentary [22] in terms of disease activity, pain, and function. This information is particularly useful to be taken into account in an appropriate medical advice and public health recommendations.

\section{Social and economic impact of rheumatoid arthritis}

The increase in life expectancy has raised the frequency of chronic musculoskeletal diseases, such as rheumatoid arthritis (RA), and elevated treatment costs, generating global concern for the last decade, which was declared as the "decade of bone and joint" by the World Health Organization. A statement given by UN Secretary General Kofi Annan, declaring the Bone and Joint Decade 2000-2010, 30 November 1999: "Musculoskeletal disorders are the most common causes of severe long term pain and physical disability, affecting many millions of people across the globe. They have an enormous impact on the individual, society, and health care social systems. There are effective ways to prevent or treat these disabling conditions. But we must act on them now [23].”

RA is a chronic autoimmune disease that increases morbidity, mortality, and produces high economic costs for the patient, the family, and society, besides altering the emotional balance, thus altering the quality of life [24]. 
Here are some necessary definitions of the costs to clearly refer later:

Direct costs They are determined by the derivative of direct patient care, like: medication, hospitalization, diagnostic or therapeutic interventions, professional fees, transportation, mechanical aids for the patient, physiotherapy, as well as nursing value.

Indirect costs Are those that come from paying disabilities.

Intangible costs They are difficult to estimate, since they result from the reduction in earning capacity or decrease in life expectancy [25, 26].

Without delving exhaustively, costs must be differentiated before and after biologic agents, since these increased between 3-6 times and have moved hospitalization expenses as those responsible for the high cost, as indicated by studies in the USA and Europe [26, 27]. Michaud et al., in their cohort, found a cost of US\$6164/year when synthetic diseasemodifying antirheumatic drugs (DMARDs) are used, compared to US\$19,016/year with biologics [26]. A similar situation was observed in a French study [27]. However, with the introduction of the combined therapy and biologics, we have seen positive results, not only in the clinical aspect but also in the indirect costs that are reflected in decreased hospital days, decreased sick leave, and therefore, decrease of absenteeism, with increased employment of patients, both men and women $[28,29]$. Another positive topic, as reported by Huscher et al., is that there is an absence of a steady increase in drug costs, since it is estimated that, after 7 years, a plateau in the curve of costs is reached by biologics [30]. But some doubts remain regarding the possible success, as the sense of well-being and the intensity of pain does not improve over time through a decade [28].

Another relevant aspect is that there are factors of the same disease that increase costs; for example, if the disease has a duration of more or less than 6 months, significant differences are established, with greater cost and with more disease duration, and the same phenomenon occurs with the number of comorbidities [25]. With respect to HAQ, there is an exponential relationship, as a higher score implies higher costs, as much as one point increase represents a cost of US\$8084/year [26, 31].

An indirect cost related to AR is the work stoppage. In a study of 133 patients with 3 years of follow-up since the onset of the disease, 78 (59\%) continued working, 23 (17\%) were retired due to RA, $12(9 \%)$ lost their jobs but did not receive pension, and $20(15 \%)$ were out of the workforce for reasons other than RA causes [32].

In Latin America, there are few studies on costs in RA, but they generally agree with the above (Table 1). A study in Mexico by Ariza et al. indicates the lowest cost in the region in relation to the exclusive use of synthetic DMARDs [33]; along with the study of Buenogens et al. [34], they are based on real-life patients. A Colombian work, conducted by Mora et al., is a simulation study and represents an important contribution that provides a categorization based on disease activity, demonstrating that high disease activity translates into increased direct cost, fundamental basis in drug costs, becoming similar to those of other first world countries [35].

\section{Rheumatologist perspective}

Undoubtedly, in recent decades, there has been a qualitative change in the confrontation of RA, because, in the first place, it was recognized as a severe disease that turned the existing paradigm even in the second half of the last century; this led to design strategies to achieve earlier diagnosis, such as the development of early arthritis clinics that have allowed us not only to distinguish RA from other early inflammatory arthritis but also to recognize patients with more aggressive disease, and, in conjunction with the above statement, to set treatments according to the aggressiveness, such as combination therapy with methotrexate as the cornerstone of treatment. Finally, the appearance of anti-TNF agents and other biologics, which are similar to combination therapy, have been a step forward in searching for a better disease control and, certainly, a better prognosis. We consider that the establishment of new classification criteria for RA will result in strengthening the possibility of an early diagnosis of a serious disease.

Taking this into consideration has led a new positioning of the rheumatologist as the leader of an interdisciplinary team with greater strength, security, and optimism in his results. We all hope that, in the nearest future, the cost of biologic agents will decrease, and with the decrease of indirect and intangible costs, these drugs will be more accessible for the general population.

The above expectations are not free of any danger, since the rheumatologist often feels pressure, not only by health-care providers but also by the patients themselves, who, in their anxiety about their illness and knowledgeable about the existence of biologic therapy, demand for its early use, even without previous evaluation of synthetic DMARDs. We think that their behavior is influenced by the pharmaceutical industry.

Finally, we think that if we compare our current practice with the past, the current scenario will contain much less frustration and hopelessness than the one lived by rheumatologists 40 years ago, and, for patients, the future is safer, even in countries like those in Latin America. 
Table 1 Comparison of costs in patients with rheumatoid arthritis in Latin America

\begin{tabular}{lllllll}
\hline Country/year & Total direct costs US\$ & Drug costs (\%) & Medical costs (\%) & Other costs (\%) & Synthetic DMARDs & Biologic agents \\
\hline Mexico 2005 (12) & 1735 & 25.76 & 51.33 & 22.9 & Yes & Do not \\
Brazil 2008 (13) & 14,185 & 90.8 & 6.8 & 2.4 & Yes & Yes \\
Colombia 2009 (14) & $1,689-23,441^{\text {a }}$ & 86 & 14 & - & Yes & Yes \\
\hline
\end{tabular}

${ }^{\text {a }}$ Depending on the rate of activity of the AR

\section{Illness or disease? A life with rheumatoid arthritis: the words from a patient}

\begin{abstract}
A large part of the cultural discord that exists between patients and clinicians lies in the inherent difference between the patients' subjective experience of "illness" and the clinician's objective approach to "disease" [36].
\end{abstract}

We cannot start talking about the experience of living with rheumatoid arthritis without taking some time to look at this definition, written several years ago, but still so current. And this is the case because it is not only a body that gets affected, and it is not just a disease. Living with rheumatoid arthritis means to experience deep transformations in different areas in life: love, family, social life, job, to mention just a few; to live the subjective experience of illness.

One of the narrations shared by patients with rheumatoid arthritis concerns with some questions that arise after the diagnosis: why, why me, what did I do wrong? The attempt to associate a traumatic event and the appearance of the first symptoms is also recurrent, which somehow-true or notenables you to make sense of the transformation of the SELF many of us go through. Already in the year 1981, Baron stated: "people do not come in for diagnosis and treatment; they come to be made well, made whole, to recover the sense of health, of being well, fully alive, in-the-world [37]."

Readapting life is probably a term as valued by patients with rheumatoid arthritis as remission, for being well, fully alive implies a learning process, well summarized by this young Chilean patient: "rheumatoid arthritis has given me the gift of awareness to accept I am a vulnerable woman, who feels and makes mistakes; courage to face my fears; passion to live each day as if it was the last, understand life is today and appreciate everything that shows up in my space; gratitude to realize I have a wonderful family that takes care of me, and gives me containment and support; and faith, because I am certain that arthritis is just the symptom coming to show me the unlearned lesson."

Achieving a good re-adaptation or learning process depends on at least five factors that we have been able to identify working with these patients:
Access to treatment Latin America undergoes a very dissimilar reality with regards to access to therapies. Nevertheless, there is a common feeling concerning the financial decay generated by the difficulty to keep a steady job due to the symptomatology of the disease. An Argentinean young woman tells it with a touch of humor that does not hide how dramatic this situation is: "I don't know what hurts more, my joints or the fact that what I make is not enough to cover all my expenses. Since I got sick, my financial situation worsened.” Treatment does not only imply medicine; treatment also means to have an appropriate job, where you are still an active member of society, physical therapy, and body re-education, among others.

Social integration Counting on family, friends, or coworkers who understand what you go through is comforting. Part of the process each one goes through is that of accepting the new limitations. If they have to be constantly hidden, this acceptance takes more than needed, thus delaying the re-learning process. But the doubt that constantly arises is how to make the other a part of an invisible pain that very often appears and disappears with no explanation? The experience of chronic pain affects the state of mind, and therefore, social relationships.

Being recognized as "experts" If we added up the hours we spend with the clinical treating team, they would not add up to more than a couple of days in a year. This condition is with us on a daily basis. Therefore, certainly the ones who know better than anyone else how it manifests, how it affects, or possible ups and downs are the patients themselves. The fear to express something experienced as reality very often affects the adherence to any treatment and, above all, the self-management

Table 2 Patient and clinician share expertise

\begin{tabular}{ll}
\hline Patient & Clinician \\
\hline Expertise of illness & Diagnosis \\
Social circumstances & Disease etiology \\
Attitude to risk & Prognosis \\
Values & Treatment options \\
Preferences & Outcome probabilities \\
\hline
\end{tabular}


process that every person living with a chronic condition requires. As defined by Angela Coulter, it is necessary to learn about sharing expertise [37] and summarized in Table 2. Understanding and respecting everybody's scope of action enables the movement towards a healthier and stronger physician-patient relationship. Expert patients are "people who have the confidence, skills, information, and knowledge to play a central role in the management of life with chronic diseases and to minimize the impact of disease on their lives" [38].

First-hand quality information Making decisions dealing with one's own health and life in general is a process whose frequency and motivation very often depend on how rooted this practice is within one's own culture. When it comes to approaching chronic diseases, this is a central process of self-management. Making decisions requires having the best information available. Most of the time, the patient expects that information to be given by someone in the group where they put their trust: a member of their clinical team. Patients' and clinicians' communication skills are critical to pushing forward with this process, so as to select everything that is important, but at the same time, present it in a way that the other can understand.

Peer support and social networking The great need to rely on people who understands the process that you are going through has led in recent years to a sharp rise in the amount of social networks available for patients with rheumatoid arthritis. In these virtual groups, not only the support and understanding very often required are found but also experiences regarding the disease are shared, which enable better management. Nevertheless, without a clear understanding of what role each of them plays in the process, situations can come up in which among patients there are recommendations on what drugs or dosage to use. Once again, a good partnership between physicians and patients can build a better virtual space. Living a life with rheumatoid arthritis is a life in which you have to take charge of an illness and a disease, and to do so, a strong partnership between clinicians and patients is undoubtedly the best strategy.

An integrated approach to rheumatoid arthritis requires not only substantial improvements in public policies in each of our countries but also progress in the clinician-patient relationship towards informed, shared decision-making and patientcentered care. We know it is a long way, but we want to be a part of it. Let us help!

\footnotetext{
${ }^{1}$ Let us help! is inspired by David deBronkart's quote "Please, let patients help improve healthcare. Let patients help steer our decisions, strategic and practical. Let patients help define what value in medicine is."
}

\section{Rheumatoid arthritis and priority health problems}

Rheumatic diseases represent a complex group of health problems that produce diverse degrees of pain, suffering, disability, and poor quality of life. If not properly treated a decreased survival is also detected [1].

Rheumatologists have been struggling for many years in different health care environments to improve patient care. Latin America has important challenges in terms of epidemiologic transition. Our region still has multiple health-care needs that are common to developing countries such as maternal and health-care problems, infections, addictions, violence and at the same time they need to provide adequate care to chronic diseases commonly seen in developed countries such as obesity, diabetes, hypertension, cancer, and rheumatic diseases. A recently published survey on global disability found that RA was ranked as the 42nd highest contributor to global disability, just below malaria and just above iodine deficiency [38].

Health-care budgets need to establish priorities that take into account several approaches [39]. Exclusion of rheumatic diseases is a common finding in these exercises since burden of illness is frequently taken into account and the low prevalence of RA does not compete with other large health-care problems such as hypertension, type 2 diabetes mellitus, malnutrition, and maternal health. Other criteria that include preventive interventions and cost-effective interventions are not easily justified to reach a priority.

Political issues dominate some decisions, and rheumatology societies have not delivered yet solid local information to be used by policy makers.

Smart strategies should be proposed to gather more and better knowledge, incorporate the concept of quality of life in a multi dimensional concept decision process. Rheumatology societies should be part of teams of decision makers and plan organized strategies that need to be consistent with the final ideal of better health from a societal perspective.

Rheumatologists need to be aware that adequate clinical and therapeutic decisions should always take into account the rational use of resources in our patients in the context of societies looking for equity.

Regional decisions should try to produce better outcomes using optimized strategies in our patients. Rheumatologists have a great potential to change this perspective that leaves out rheumatoid arthritis and other rheumatic diseases from priority health list in the region, by performing coherent activities to positively change health care of rheumatic patients in Latin America.

Open Access This article is distributed under the terms of the Creative Commons Attribution 4.0 International License (http:// creativecommons.org/licenses/by/4.0/), which permits unrestricted use, distribution, and reproduction in any medium, provided you give appropriate credit to the original author(s) and the source, provide a link to the Creative Commons license, and indicate if changes were made. 


\section{References}

1. Boonen A, Severens JL (2011) The burden of illness of rheumatoid arthritis. Clin Rheumatol 30:S3-S8. doi:10.1007/s10067-0101634-9

2. Peláez-Ballestas I, Sanin LH, Moreno-Montoya J et al (2011) Epidemiology of the rheumatic diseases in Mexico. A study of 5 regions based on the COPCORD methodology. J Rheumatol Suppl 86:3-8. doi:10.3899/jrheum.100951

3. Scublinsky D, Venarotti H, Citera G, Messina OD, Scheines E, Rillo O et al (2010) The prevalence of rheumatoid arthritis in Argentina: a capture-recapture study in a city in Buenos Aires province. J Clin Rheumatol 16:317-321. doi:10.1097/RHU.0b013e3181f3bfdd

4. Quintana R, Silvestre A, Goñi M et al (2013) "Prevalencia de malestares músculo-esqueléticos y enfermedades reumáticas en población originaria qom (toba) de la ciudad de rosario", comunicacion oral. 46 Congreso Argentino de Reumatología, Mar del Plata

5. Widdifield J, Paterson M, Bernatsky S et al (2014) The epidemiology of rheumatoid arthritis in Ontario. Can Arthritis Rheum 66: 786-793. doi:10.1002/art.38306

6. Del Rincón I, Battafarano ID, Arroyo RA et al (2003) Ethnic variation in the clinical manifestation of rheumatoid arthritis: role of HLA-DRB1 alleles. Arthritis Rheum 49:200-208

7. Morgan AW, Thomson W, Martin SG et al (2009) Reevaluation of the interaction between HLA-DRB1 shared epitope alleles, PTPN22 and smoking in determining susceptibility to autoantibody positive and autoantibody negative rheumatoid arthritis in a large UK Caucasian population. Arthritis Rheum 60:2565-2576. doi:10. 1002/art.24752

8. Lo SF, Huang CM, Lin HC et al (2005) Association of CYP17 gene polymorphism and rheumatoid arthritis in Chinese patients in central Taiwan. Rheumatol Int 25:580-584

9. Herráez DL, Martínez-Bueno M, Riba L et al (2013) Rheumatoid arthritis in Latin Americans enriched for Amerindian ancestry is associated with loci in chromosomes 1, 12, and 13, and the HLA Class II region. Arthritis Rheum 65:1457-1467. doi:10.1002/art.37923

10. de Rooy DPC, van Nies JAB, Kapetanovic MC et al (2014) Smoking as a risk factor for the radiological severity of rheumatoid arthritis: a study on six cohorts. Ann Rheum Dis 73:1384-1387. doi:10.1136/annrheumdis-2013-203940

11. Abhishek A, Butt S, Gadsby K et al (2010) Anti-TNF- $\alpha$ agents are less effective for the treatment of rheumatoid arthritis in current smokers. J Clin Rheumatol 16:15-18. doi:10.1097/RHU. 0b013e3181ca4a2a

12. Lu B, Solomon DH, Costenbader KH et al (2014) Alcohol consumption and risk of incident rheumatoid arthritis in women. A prospective study. Arthritis Rheum 66:1998-2005. doi:10.1002/ art.38634

13. Jin Z, Xiang C, Cai Q et al (2014) Alcohol consumption as a preventive factor for developing rheumatoid arthritis: a dose-response meta-analysis of prospective studies. Ann Rheum Dis 73:1962_ 1967. doi:10.1136/annrheumdis-2013-203323

14. Koziel J, Mydel P, Potempa J (2014) The link between periodontal disease and rheumatoid arthritis: an updated review. Curr Rheumatol Rep 16:408. doi:10.1007/s11926-014-0408-9

15. Al-Katma MK, Bisada NF, Bordeaux JM et al (2007) Control of periodontal infection reduces the severity of active rheumatoid arthritis. J Clin Rheumatol 13:134-137

16. Hart JE, Laden F, Puett RC et al (2009) Exposure to traffic pollution and increased risk of rheumatoid arthritis. Environ Health Perspect 117:1065-1069. doi:10.1289/ehp.0800503

17. Parks CG, Wallit BT, Pettinger M et al (2011) Insecticide use and risk of rheumatoid arthritis and systemic lupus erythematosus in the
Women's Health Initiative Observational Study. Arthritis Care Res 63:184-194. doi:10.1002/acr.20335

18. Pedersen M, Jacobsen S, Klarlund M et al (2006) Socioeconomic status and risk of rheumatoid arthritis: a Danish case-control study. J Rheumatol 233:1069-1074

19. Crowson CS, Matteson EL, Davis JM 3rd et al (2013) Contribution of obesity to the rise in incidence of rheumatoid arthritis. Arthritis Care Res 65:71-77. doi:10.1002/acr.21660

20. Sandberg MEC, Bengtsson C, Källberg H et al (2014) Overweight decreases the chance of achieving good response and low disease activity in early rheumatoid arthritis. Ann Rheum Dis 73:20292033. doi:10.1136/annrheumdis-2013-205094

21. Baker JF, Østergaard M, George M et al (2014) Greater body mass independently predicts less radiographic progression on X-ray and MRI over 1-2 years. Ann Rheum Dis 73:1923-1928. doi:10.1136/ annrheumdis-2014-205544

22. Sandberg MEC, Wedrén S, Klareskog L et al (2014) Patients with regular physical activity before onset of rheumatoid arthritis present with milder disease. Ann Rheum Dis 73:1541-1544. doi:10.1136/ annrheumdis-2014-205180

23. Lidgren L (2003) The bone and joint decade and the global economic and health care burden of musculoskeletal disease. J Rheumatol 30(Suppl 67):4-5

24. Yelin E (2013) Economic burden of rheumatic diseases. In: Firestein GS, Budd R, Gabriel SE (eds) Kelly's textbook of rheumatology, 9th edn. Elsevier, Philadelphia, pp 440-451

25. Newhall-perry K, Law NJ, Ramos R et al (2000) Direct and indirect costs associated with the onset of seropositive rheumatoid arthritis. J Rheumatol 27:1156-1163

26. Michaud K, Messer J, Choi HK, Wolfe F (2003) Direct medical costs and their predictors in patients with rheumatoid arthritis. A three-year study of 7,527 patients. Arthritis Rheum 48:2750-2762

27. Chevreol K, Haour G, Lucier S et al. (2014) Evolution of direct costs in the first years of rheumatoid arthritis: impact of early versus late biologic initiation an economic analysis based on ESPOIR cohort. PLoS One:9 DOI: 10.137/journal.pone.0097077

28. Ziegler S, Huscher D, Karberg K et al (2010) Trends in treatment and outcomes of rheumatoid arthritis in Germany 1997-2007: results from the national database of the German collaborative arthritis centres. Ann Rheum Dis 69:1803-1808. doi:10.1136/ard.2009. 122101

29. ter Wee MM, Lems WF, Usan $H$ et al (2012) The effect of biological agents on work participation in rheumatoid arthritis patients: a systematic review. Ann Rheum Dis 71:161-171. doi:10.1136/ard. 2011.154583

30. Huscher D, Mittendorf T, von Hinuber U et al (2013) Evolution of cost structures in rheumatoid arthritis over the past decade. Ann Rheum Dis. doi:10.1136/ard-2013-204311

31. Lajas C, Abasolo L, Bellajdel B et al (2003) Costs and predictors of costs in rheumatoid arthritis: a prevalence-based study. Arthritis Rheum 49:64-70

32. Merhesdal S, Ruof J, Schöffski O et al (2001) Indirect medical costs in early rheumatoid arthritis. Composition of and changes in indirect costs within first three years of disease. Arthritis Rheum 44: $528-534$

33. Hernández-Cruz B, Ariza-Ariza R, Cardiel-Rios MH (2006) Costs of the standard rheumatology care in active Rheumatoid arthritis patients seen in a tertiary care center in Mexico city. Reum Clin 2: 124-130

34. Buenogens FB, Blatt CR, Estima AC et al (2013) Cost analysis of treatments for severe rheumatoid arthritis in a city in southern Brazil. Cad Saude Publica 29(suppl 1):81-91. doi:10.1590/0102311X00013513

35. Mora C, González A, Diaz J, Quintana G (2009) Costos directos de la artritis reumatoide temprana en el primer año de atención: 
simulación de tres situaciones clínicas en un hospital universitario de tercer nivel en Colombia. Biomedica 29:43-50

36. Baron (1981) In: Gerteis M, Edgman-Levitan S, Daley J, Delbanco T 1993 (eds) 21

37. Coulter A The expert patient: a new approach to chronic disease management for the 21st century, Department of Health NHS 11
38. Cross M, Smith E, Hoy D et al (2014) The global burden of rheumatoid arthritis: estimates from the global burden of disease 2010 study. Ann Rheum Dis 73:1316-1322. doi:10.1136/annrheumdis2013-204627

39. Baltussen R, Niessen L (2006) Priority setting of health interventions: the need for multi-criteria decision analysis. Cost Eff Resour Allocation 4:14. doi:10.1186/1478-7547-4-14 